\title{
The role of early dietary habits in dental caries development
}

Early Childhood Caries (ECC) is a
serious dental condition that occurs
during the first three years of life and
is associated with the early intake of
sugary foods, drinks, or snacks.
There is now evidence that early mal-
nutrition episodes could lead to
delay in the eruption of primary teeth
and possibly to increased caries
prevalence. Significant correlations
are present between the intakes of
carbohydrates, proteins, and fats
during infancy and several years
later in life. Infants' dietary intake is
also significantly correlated with the
dietary intake of their mothers.
Supplementing milk with vitamins
during the first several years of life
leads to reduction in the prevalence
of linear enamel hypoplasia, a condi-
tion that may be associated with
future development of dental caries.
There are equivocal findings concern-
ing the value of using dietary habits
to predict caries incidence during
the first three years of life. There is a
need for development of educational,
nutritional, and prevention programs
targeting mothers and infants and
for research on effective methods to
prevent Early Childhood Caries.

$\mathbf{R}$ ecent epidemiological studies have found that the first year of life is an important period for the eruption of teeth and the development of dental fluorosis and dental caries later in life. ${ }^{1,2}$ If these observations are confirmed, then programs should be developed to promote oral health through early educational and preventive interventions. Currently, scientific evidence evaluating the extent of the problem of early childhood caries, and strategies to prevent it, are scarce. ${ }^{3}$

This paper reviews the epidemiological evidence of the impact of early-life diet and nutrition on ECC, the association between early diet and dietary habits later in life, and the association between parents' and infants' dietary intakes. Relevant papers were identified in the following databases: Medline, National Library of Medicine, USA; and the Nutrition Database, Commonwealth Agricultural Bureau, United Kingdom. These two databases were searched for documents that include the following terms or words: early dental caries, nutrition, diet, neonates, infants, early childhood, dietary habits, nursing caries, and baby-bottle tooth decay. The search included all papers published in English between January, 1965, and January, 1996.

\section{Epidemiology of ECC}

In Sweden, the prevalence of early childhood caries ranged from a low of $0.5 \%$ in the first year of life to $30 \%$ during the third year of life. ${ }^{4,5}$ Data from Sweden also showed that while dental caries prevalence has declined significantly in four-year-old children during the last 20 years, the prevalence of high dental caries ( $>10$ decayed, missing, and filled primary teeth) remained around 6-7\%.6 A similar observation was made by Anderson when examining 12-yearold children in Somerset, United Kingdom.? In some parts of the USA, the prevalence of ECC was between $50 \%$ and $70 \% .8$

Even though the overall prevalence of early childhood caries is relatively low in most parts of North America, the condition is a costly one to manage. In some Native American communities, the cost of treating a single case of one type of early childhood (nursing) caries under general anesthesia was reported to be around $\$ 2,000$ (US). ${ }^{10}$ The factors that lead to the development of ECC are not yet fully identified. Dietary factorsespecially the use of sugary drinks, including milk, at bedtime or during sleep-are associated with increased risk of developing ECC. Recent evidence indicates that there may be other determinants.

\section{Early malnutrition: a risk factor in ECC}

Most epidemiological studies have not found a strong association between malnutrition and dental caries prevalence..$^{11}$ Malnutrition, however, is a dynamic state, and correlating malnutrition as assessed at one point in time with the prevalence or incidence of a chronic and slowly 
progressing disease, like dental caries, has limited validity. To evaluate the effect of malnutrition on susceptibility to dental caries, a longitudinal study is required where teeth are followed pre- and post-developmentally.

Such a design was recently used in a study $y^{1,12-14}$ that evaluated the effect of malnutrition early in the lives of children on the development and eruption of primary teeth and dental caries development later in life. Tooth eruption and dental caries development were followed in a group of Peruvian children who were recruited when they were infants between the ages of 6 and 11 months. Evaluating their weight and height measurements assessed the infants ${ }^{\prime}$ nutritional status. These measurements were compared with the standards for weight and height of the United States' National Center for Health Statistics. The infants were classified as to whether they were:

(a) Normal-height-for-age (HA) was more than $95 \%$ of standard, and normal weight-for-height (WH) was more than $95 \%$ of standard;

(b) Wasted (acute malnutrition)normal HA but low WH (less than $90 \%$ of standard);

(c) Stunted (past malnutrition)-low HA (less than $95 \%$ of standard) and normal WH; or

(d) Stunted and wasted. Acutely malnourished infants were provided with nutritional and medical counseling, and they recuperated shortly after recruitment into the study. ${ }^{14}$ The children were examined every 4-6 months until they reached the age of four years.

This longitudinal study found that the eruption of primary teeth was delayed in the stunted, wasted, and stunted/wasted infants in comparison with healthy infants. The delay of eruption persisted until the age of $2.5-3$ years. At the age of four years, children who were stunted and wasted had a significantly higher mean number of decayed, extracted, and filled primary teeth (deft). ${ }^{14}$ The stunted and wasted children had a bi-modal caries distribution with a definite high-risk group that included $17.2 \%$ of the severely malnourished children.

Two years after the final examination in the longitudinal study, ${ }^{14}$ a reexamination of a subsample of the children in the original study found that the eruption of permanent incisors and first permanent molars was accelerated in the malnourished children. ${ }^{1}$ A significantly higher prevalence of dental caries in the primary and permanent dentitions was observed in the stunted and wasted children compared with healthy children.

The investigators concluded that a single moderate malnutrition episode occurring in infancy could possibly result in increased dental caries later on in life..$^{1,14}$ While these findings are important in this period where malnutrition crises erupt frequently around the world, the studies by Alvarez et al. ${ }^{13,14}$ did not account for the differences in sugar intake of the examined children, and hence, a definite conclusion about the long-term impact on dental caries development of a single malnutrition episode in early infancy cannot be reached. The presence of a high-risk group with caries afflicting smooth surfaces may also indicate a high sugar intake by the children. The investigators did not provide data that could be used to test this hypothesis.

\section{Linear enamel hypoplasia, malnutrition, and dental caries}

Given the difficulty of determining early malnutrition status in crosssectional epidemiological studies, investigators have used linear enamel hypoplasia as a proxy for the presence of early malnutrition. ${ }^{15-17}$ Linear enamel hypoplasia appears as bandlike or circumferential irregularities in enamel that may be pitted. It appears as a gray-yellow, brown, or black band that runs parallel to the incremental lines of enamel in the middle part of the facial surface of a tooth. Enamel hypoplasia was crosssectionally associated with higher dental caries prevalence, ${ }^{16,17}$ and a recent study found an association between hypoplasia and colonization with cariogenic bacteria. ${ }^{18}$ Similar to the studies of the association between malnutrition and dental caries, these studies were bivariate in design and evaluated both conditions at one point in time. Moreover, the children with linear enamel hypoplasia suffered from general infections during the first month of their lives, ${ }^{16}$ and hence, a confounding effect is introduced that may have biased the association between enamel hypoplasia and dental caries. An association among enamel hypoplasia, malnutrition, and dental caries could also be confounded by other systemic conditions, ${ }^{19,20}$ such as low birth weight ${ }^{21}$ and calcium deficiency, ${ }^{22}$ that may disrupt the development of the enamel matrix.

Linear enamel hypoplasia is used by anthropologists as an indicator of early childhood disease. ${ }^{23}$ For example, in human skeletal remains extracted from the Monroe County Poorhouse Cemetery, that was in use between 1826 and 1863, linear enamel hypoplasia peaked around the age of 2.5-3 years in the permanent maxillary central incisors. ${ }^{23}$ One hypothesis for the development of linear enamel hypoplasia that is advocated by anthropologists suggests that stress associated with weaning probably leads to the development of this enamel defect. ${ }^{23}$ In the absence of data on infections, malnutrition, and occurrences of febrile illnesses early in life, it is difficult to pinpoint the exact reason for the occurrence of linear enamel hypoplasia.

Evaluations of the evidence from community field trials show that malnutrition or reduced protein-energy intake could lead to the development of linear enamel hypoplasia. In Mexico, Goodman et al. ${ }^{24}$ tested the effect on enamel hypoplasia of providing a fluid containing powdered milk and vitamins pre- and postnatally during the first several years of life. The 15-year-old adolescents who had received supplements had a significant reduction in the development of linear enamel hypoplasia on maxillary central incisors in compari- 
son with the incidence in nonsupplemented adolescents. The relative risk that a right central maxillary incisor developed hypoplasia in nonsupplemented relative to supplemented adolescents was 9.3. In another study, in Guatemala, May et al evaluated the effect of caloric supplements in addition to retinol, ascorbic acid, and vitamins ( $A$, niacin, and thiamine) on the development of linear enamel hypoplasia. ${ }^{20}$ Supplementing the diet with vitamins resulted in a 50\% reduction in linear enamel hypoplasia.

These recent community trials show that nutritional supplement of diet early in life leads to a significant reduction in enamel hypoplasia. Unfortunately, these studies did not evaluate the development of dental caries. If linear enamel hypoplasia is caused by malnutrition, and if it is associated with an increased risk of colonization with cariogenic bacteria and developing dental caries, then an association between these two conditions (hypoplasia and dental caries) should be evident. The most recent epidemiological study that investigated this question was conducted in Tanzania. ${ }^{15}$ The association among nursing caries, linear hypoplasia, and weaning habits was evaluated in children selected from a region in that country. In a case-control comparison, the odds ratio of developing rampant caries was 15.6 higher in children who had linear hypoplasia compared with those who had no hypoplasia. ${ }^{15}$ While this new study confirmed the observations of previous investigators, ${ }^{16,17,25}$ the definition of linear enamel hypoplasia may have included incipient caries lesions as well as true linear enamel hypoplasia. If so, the question becomes whether the presence of incipient caries in children leads to higher odds of developing dental caries.

In conclusion, the new studies of the association between malnutrition and dental caries, while not totally conclusive, indicate the need for further investigation of the emerging hypothesis that early malnutrition may have a long-term detrimental effect on dental health. The information presented in the previous section supports a re-examination of the effect of early diet on dental caries development.

\section{Early dietary intake}

There is evidence that early diet affects brain growth and bone mineralization of pre-term infants. ${ }^{26-28}$ There is also evidence that early diet is a determinant of later dietary habits and that the dietary habits of mothers are associated with those of their offspring, at least during the first several years of life.

There is an association between serum cholesterol levels of infants and the cholesterol levels measured nine years later..$^{29}$ About a quarter of the infants who had high cholesterol levels (> $200 \mathrm{mg} / \mathrm{dL}$ ) (at-risk group) had high levels in follow-up examinations conducted nine years later. Only $8 \%$ of the infants who initially had low serum cholesterol levels had high levels after nine years. Infants with high cholesterol levels tended to consume a significantly higher percentage of cholesterol-containing foods per 1,000 Kcal compared with the children in the control group. ${ }^{29}$

Another study of early dietary intake, the Bogalusa Heart Study, 30,31 was designed to evaluate the early natural history and risk factors of coronary artery disease and hypertension. The Spearman rank correlation coefficients between the dietary intakes at ages 2 and 4 years were significant for total protein $(\mathrm{r}=0.65)$, animal protein $(r=0.46)$, total sugar $(r=0.39)$, sucrose $(r=0.37)$, starch $(r$ $=0.33)$, total fat $(r=0.53)$, saturated fatty acid $(r=0.48)$, polyunsaturated fatty acid $(r=0.43)$, and cholesterol ( $r$ $=0.49$ ). Between $47 \%$ and $65 \%$ of those in the upper third for total fat and cholesterol intakes at 2 years of age remained in the upper third at the age of four years. ${ }^{31}$

Dietary patterns seem to be established early in life. ${ }^{32}$ In a two-year follow-up of the consumption of soft drinks and sweets of 231 Norwegian children, significant correlations were found between the consumption of sweets at the age of 10 months and 2 years $(r=0.47)$, and also between the consumption of soft drinks at both ages $(r=0.26)$. There was also a significant correlation between the intake of sweets and soft drinks at the age of 2 years $(r=0.36) .32$

\section{Dietary intake of parents}

Do parents play a role in determining the dietary habits of their children? One major study that investigated this question is the Framingham Children's Study, where three-day food diaries were kept for 116 fami$\operatorname{lies}^{33}$ at three-month intervals for a period of a year. Significant correlations were found between mothers' and daughters' intake of protein $(r=0.42)$, carbohydrates $(r=0.47)$, total fat $(r=0.49)$, cholesterol $(r=0.56)$, sodium $(r=0.44)$, potassium $(r=0.43)$, and fatty acids $(r=0.35-0.51)$. The association between mothers' and sons' intake were significant for carbohydrates $(r=0.28)$, total fat $(r=0.40)$, fatty acids $(r=0.31-0.43)$, sodium $(\mathrm{r}=0.27)$, and calcium $(\mathrm{r}=0.22)$. There was no significant association between the dietary intakes of the fathers and daughters. The dietary intake of the fathers was associated only with their sons' intake of saturated fatty acid $(r=0.40)$ and cholesterol $(r=0.45)$.

Long-term correlations were found between the use of a sweetened feeding bottle in infancy and the child's intake of sugar at the ages of eight to 10 years. ${ }^{34}$ Of the children of the mothers who reported that they had provided a sweetened feeding bottle during infancy, $72 \%$ had high sugar intake at the ages of eight to 10 years, compared with $28 \%$ of the children of the mothers who did not provide sweetened bottles. Dental caries prevalence in threeyear-old children with high exposure to sugar during infancy was significantly higher than that of the children who were less exposed to sugar. Paunio in Finland ${ }^{35}$ also reported similar findings.

Breast-feeding is promoted by all health organizations because of its potential benefit in protecting against infections and delaying the onset of Type I diabetes mellitus. ${ }^{36-38}$ There 
are no clinical trials that have tested the effect of breast-feeding on early childhood caries. Cross-sectional studies have associated prolonged breast-feeding ${ }^{39}$ and the habit of allowing infants to sleep with the breast nipple in their mouths with early childhood caries. ${ }^{15}$

In conclusion, dietary intake of children is strongly associated with their mothers' dietary intakes and their own dietary habits developed early in life. Sugar consumption is of particular importance to dental caries, and it seems that the frequent use of a sweetened feeding bottle, soft drinks, and sweets early in life could contribute to a higher consumption of sugary items later in life.

\section{Prediction of ECC}

If sugar consumption during the first year of life influences the level of sugar intake later in life, then could the early consumption of sugar be used to predict future caries development in children? The small numbers of prediction studies of early childhood caries provide an equivocal answer to this question. In a Swedish study, higher education of mothers was strongly associated with higher consumption of noncariogenic foods and lower consumption of sucroserich foods. ${ }^{40}$ Comparison between children with and without caries at the age of three years showed that those who developed dental caries had a higher consumption of sucroserich foods at the age of 12 months compared with children who did not develop caries. No evaluation, however, of the accuracy of the model in predicting dental caries was presented. ${ }^{40}$

In another Swedish study, ${ }^{41}$ that followed children at the ages of 18 and 36 months, dental caries incidence was associated with dietary intake. The clinical examination evaluated oral hygiene status, gingival bleeding, and dental caries. Salivary levels of lactobacilli and mutans streptococci were also measured. Almost half of the children consumed, more than twice a day, sugarcontaining foods, drinks, or snacks.
The proportion of children with high daily sugar intake was consistent at the ages of 18 and 36 months. None of the risk factors measured was able to predict dental caries occurrence with validity. Frequent sugar consumption had a positive predictive value of 0.26 , indicating that $74 \%$ of children with a relatively high frequency of sugar intake (fewer than 7 sugar exposures per week) did not develop caries between the ages of 18 and 36 months.

The answer to the question posed in this section is not currently available. The prediction of dental caries is definitely necessary to identify families where targeted educational and prevention efforts should be directed to reduce the potential of developing early childhood caries. Any model should include indicators of social, cultural, and biological risk factors of dental caries in infants and mothers that can validly and reliably be used to predict early childhood caries. The association among diet, cariogenic bacteria, and immunology responses in saliva definitely needs further study.

\section{Discussion}

Early childhood caries presents a challenge not only to dental professionals but also to other health professionals. ${ }^{42}$ The limited evidence that exists today on this problem should not deter us from developing oral health promotion programs to prevent the occurrence of this condition. Dietary habits are formulated early in life, and a mother's choice of foods is a strong determinant of her offspring's dietary habits. ${ }^{29,30}$ To prevent the development of early childhood caries, mothers in areas with high dental caries prevalence should be targeted with pre- and post-natal health promotion programs. Since the first professional contact with pregnant mothers, and with their infants immediately after delivery, occurs in medical offices, nurses or physicians should provide nutritional advice and information on prevention of early childhood caries.

Unfortunately, we have not paid enough attention to the crucial role played by mothers in promoting oral health. ${ }^{3}$ The individuals most susceptible to dental disease are those who usually do not visit dental offices regularly. Therefore, dentists cannot approach this vulnerable group through their regular re-call efforts. There is evidence that low-income mothers lack information on the role of the dental profession in prevention and lack the knowledge on how to prevent oral diseases. ${ }^{43}$ Mothers in some developing countries have a tendency to provide sugary products to their children early in life and use sugar as a reward. ${ }^{44,45}$

At present, there are no good scientific evaluations of interventions to prevent early childhood caries.

Reductions of infection with cariogenic bacteria in mothers, in addition to the use of fluoride and restorations, were successful in preventing dental caries in children. ${ }^{46}$

Unexpectedly, the study by Aaltonen and Tenovuo ${ }^{47}$ has shown that early frequent salivary contacts between infants and mothers before primary teeth erupt (less than 7 months of age) was associated with protection against dental caries in the primary dentition four years later. Hence, it may be concluded, based upon the finding of this cohort study, ${ }^{47}$ that seven-month-old infants exposed 3 times or more per day to their mother's saliva (through sharing of utensils, direct kissing, tasting of foods, and using pacifiers wetted with the mother's saliva), get "immunized" against subsequent infection with mutans streptococci that would most likely colonize the mouth when the primary teeth erupt. This hypothesis should be validated, because it has important implications for caries prevention.

With regard to early malnutrition, the study by Alvarez et al. ${ }^{14}$ supports the hypothesis that early childhood caries may possibly be associated with early malnutrition episodes. In population studies in developed countries, early malnutrition may not be detected because it is episodic and could have been managed during infancy. Consequently, the effect of a 
single malnutrition episode during tooth development on future susceptibility to dental caries is difficult to investigate. The study by Alvarez et al. ${ }^{14}$ needs to be replicated using a longitudinal multifactorial design and a high-risk population in North America.

The data presented on the association between early dietary habits of mothers and infants raise several questions. Behavioral modeling at home is an important factor in shaping the fat, protein, and carbohydrate intake of children. The findings from the study by Vobecky et al. ${ }^{29}$ support the hypothesis proposing the presence of a "fat gene" that determines the level of cholesterol intake in children and influences their dietary choices. ${ }^{48}$ There is also evidence that environmental factors, principally the mothers' diet, influences the dietary habits of children. ${ }^{33}$

One oral condition that seems to interest anthropologists more than oral epidemiologists is linear enamel hypoplasia. ${ }^{23}$ North American oral epidemiologists have also been reluctant to diagnose incipient caries lesions. ${ }^{3}$ Consequently, we have no useful data on carious and non-carious enamel lesions and their relevance in the prediction of dental caries and the management of the disease. Studies of early malnutrition and diet should include diagnosis of early caries lesions and enamel hypoplasia to allow for a detailed analysis of the potential effect of malnutrition on tooth development and increased susceptibility to dental caries.

In conclusion, I concur with Weinstein ${ }^{3}$ that research in early childhood caries suffers from a lack of interest and a lack of scientific information that could assist in developing oral health promotion programs. The data presented in this review indicate that this area should receive more attention by funding agencies. Living a healthy life is rooted in our development during the first few years of life. To change dietary patterns, increase the resistance to disease, and achieve a healthy life-style require focused attention on nutritional, psychological, and behavioral development during the early years of life.

Dr. Ismail is Professor, Department of Dental Clinical Sciences, Faculty of Dentistry, Dalhousie University, 5981 University Avenue, Halifax, Nova Scotia B3H 3J5, Canada. Currently, he is a professor at the Department of Cariology, Restorative Sciences, and Endodontics, School of Dentistry, The University of Michigan, 1011 N. University D2361, Ann Arbor, MI 48109-1078.

Presented at a symposium entitled "Nutrition and Prosthodontics-The Inter-relationship of Diet, Nutrition, and Oral Health", held during the 74th General Session of the International Association for Dental Research, March 13, 1996, San Francisco, CA. The symposium and the publication of these proceedings are supported by the Block Drug Co.

1. Alvarez JO. Nutrition, tooth development, and dental caries. Am J Clin Nutr 61(Suppl):410S-6S, 1995.

2. smail AI, Messer JG. The risk of fluorosis in students exposed to a higher than optimal concentration of fluoride in well water. J Public Hlth Dent 56:22-7, 1996.

3. Weinstein P. Research recommendations: pleas for enhanced research efforts to impact the epidemic of dental disease in infants. J Public Hlth Dent 56:55-60, 1996.

4. Wendt L-K, Hallonsten AL, Koch G. Dental caries in one- and two-year-old children living in Sweden. Part I-A longitudinal study. Swed Dent J 15:1-16, 1991.

5. Wendt L-K, Hallonsten A-L, Koch G. Oral health in preschool children living in Sweden. Part II-A longitudinal study. Findings at three years of age. Swed Dent J 16:41-9, 1992.

6. Holm AK. Caries in the preschool child: international trends. J Dent 18:291-5, 1990

7. Anderson RJ. Changes in dental caries experiences of 12-year-old school children in two Somerset schools: a review after an interval of 30 years. Br Dent J 179:125-9, 1995.

8. Tsubouchi J, Tsubouchi M, Maynard RJ, Domoto PK, Weinstein P. The study of dental caries and risk factors among Native American infants. J Dent Child 62:283-7,1995.

9. O'Sullivan DM, Douglass JM, Champany R, Eberling S, Tetrev S, Tinanoff N. Dental caries prevalence and treatment among Navajo preschool children. J Public Hlth Dent 54:139-44, 1994.

10. Cook HW, Duncan WK, De-Ball S, Berg B The cost of nursing caries in a Native American Head Start population. J Clin Pediatr Dent 18:139-42, 1994.

11. Burt BA, Ismail AI. Diet, nutrition, and food cariogenicity. J Dent Res 65:1475-84,
1986.

12. Alvarez JO, Lewis CA, Saman C, et al. Chronic malnutrition, dental caries, and tooth exfoliation in Peruvian children aged 3-9 years. Am J Clin Nutr 48:368-72, 1988.

13. Alvarez JO, Eguren JC, Caceda J, Navia $J M$. The effect of nutritional status on the age distribution of dental caries in the primary teeth. J Dent Res 69:1564-6, 1990.

14. Alvarez JO, Caceda J, Woolley TW, Carley KW, Baiocchi N, Caravedo L, et al. A longitudinal study of dental caries in. the primary teeth of children who suffered from infant malnutrition. J Dent Res 72:1573-6, 1993.

15. Matee MIN, Van 't Hof MA, Maselle SY, Mikx FHM, van Palenstein Helderman WH. Nursing caries, linear hypoplasia, and nursing and weaning habits in Tanzanian infants. Community Dent Oral Epidemiol 22:289-93, 1994.

16. Sweeney EA, Guzman M. Oral conditions in children from three highland villages in Guatemala. Arch Oral Biol 11:687-98, 1966.

17. Infante P, Gillespie GM. Enamel hypoplasias in relation to caries in Guatemalan children. J Dent Res 56:493-8, 1977.

18. Li Y, Navia JM, Caufield PW. Colonization by mutans streptococci in the mouths of 3- and 4-year-old Chinese children with or without enamel hypoplasia. Arch Oral Biol 39:1057-62, 1994.

19. Neiburger EJ. Enamel hypoplasias: poor indicators of dietary stress. Am J Phys Anthropol 82:231-3, 1990.

20. May RL, Goodman AH, Meindl RS. Response of bone and enamel formation to nutritional supplementation and morbidity among malnourished Guatemalan children. Am J Phys Anthropol 92:37-51, 1993.

21. Fearne JM, Bryan EM, Elliman AM, Brook $\mathrm{AH}$, Williams DM. Enamel defects in the primary dentition of children born weighing less than $2000 \mathrm{~g}$. Br Dent J 168:433-7, 1990.

22. Nikiforuk G, Fraser D. The etiology of enamel hypoplasia: a unifying concept Pediatrics 98:888-93, 1981.

23. Lanphear KM. Frequency and distribution of enamel hypoplasias in a historic skeletal sample. Am J Phys Anthropol 81:35-43, 1990

24. Goodman $\mathrm{AH}$, Martinez C, Chavez A Nutritional supplementation and the development of linear enamel hypoplasias in children from Tezonteopan, Mexico. Am J Clin Nutr 53:773-81, 1991.

25. Sweeney EA, Cabrera J, Urrutia J, Mata L. Factors associated with linear enamel hypoplasia of human deciduous incisors. J Dent Res 48:1275-9, 1969.

26. Lucas A. Does early diet program future outcome? Acta Paediatr Scand 365(Suppl):58-67, 1990.

27. Lucas A, Morley R, Cole TJ, Gore SM, Davis JA, Bamford MFM, et al.. Early diet 
in preterm babies and developmental status in infancy. Arch Dis Child 64:1570-8, 1989.

28. Morley R, Lucas A. Influence of early diet on outcome in preterm infants. Acta Paediatr Scand 405(Suppl):123-6, 1994.

29. Vobecky JS, David P, Vobecky J. Dietary habits in relation to tracking of cholesterol level in young adolescents: a nine-year follow-up. Ann Nutr Metab 32:312-23, 1988.

30. Arbeit ML, Nicklas TA, Frank GC, Webber LS, Miner MH, Berenson GS. Caffeine intakes of children from a biracial population: The Bogalusa Heart Study. J Am Diet Assoc 88:466-71, 1988.

31. Nicklas TA, Webber LS, Berenson GS Studies of consistency of dietary intake during the first four years of life in a prospective analysis: Bogalusa Heart Study. Am Coll Nutr 10:234-41, 1991.

32. Rossow I, Kjaernes U, Holst D. Patterns of sugar consumption in early childhood. Community Dent Oral Epidemiol 18:12-6, 1990.

33. Oliveria SA, Ellison CR, Moore LL, Gilman MW, Garrahie EJ, Singer MR. Parent-child relationships in nutrient intake: the Framingham Children's Study. Am J Clin Nutr 56:593-8, 1992

34. Silver DH. A longitudinal study of infant feeding practice, diet and caries, related to social class in children aged 3 and 8-10 years. Br Dent J 163:296-300, 1987.

35. Paunio P. Dental health habits of young families from Southwestern Finland. Community Dent Oral Epidemiol 22:3640, 1994.

36. Howie PW, Forsyth JS, Ogston SA, Clark $A$, Florey CD. Protective effect of breast feeding against infection. Br Med J 300:116, 1990.

37. Rubin DH, Leventhal JM, Krasilnikoff PA et al. Relationship between infant feeding and infectious illness: a prospective study of infants during the first year of life. Pediatrics 85:464-71, 1990.

38. Bognetti $\mathrm{E}$, Meschi $\mathrm{F}$, Malavasi $\mathrm{C}$, et al HLA antigens in Italian type 1 diabetic patients: role of DR3/DR4 antigens and breast feeding in onset of the disease. Acta Diabetol 28:229-32, 1992

39. Williams SA, Hargreaves JA. An inquiry into the effects of health related behaviour on dental health among young Asian children resident in a fluoridated city in Canada. Community Dent Hlth 7:413-20, 1990.

40. Persson L-A, Holm AK, Arvidsson S, Samuelson G. Infant feeding and dental caries-a longitudinal study of Swedish children. Swed Dent J 9:201-6, 1985.
41. Schroder U, Widenheim J, Peyron M, Hagg E. Prediction of caries in 11/2-yearold children. Swed Dent J 18:95-104, 1994.

42. Milnes AR. Description and epidemiology of nursing caries. J Public Hlth Dent 56:38-50, 1996.

43. Kay EJ, Blinkhorn AS. A study of mothers' attitudes towards the prevention of caries with particular reference to fluoridation and vaccination. Community Dent Hith 6:357-63, 1988.

44. Stacey MA, Wright FAC. Diet and feeding patterns in high risk preschool children. Aust Dent J 36:421-7, 1991.

45. Williams SA, Sahota P. An enquiry into the attitudes of Muslim Asian mothers regarding infant feeding practices and dental health. J Human Nutr Diet 3:393401, 1990.

46. Kohler B, Bratthall D, Krasse B. Preventive measures in mothers influence the establishment of the bacterium Streptococcus mutans in their infants. Arch Oral Biol 28:225-31, 1983.

47. Aaltonen AS, Tenovuo I. Association between mother-infant salivary contacts and caries resistance in children: a cohort study. Pediatr Dent 16:110-6, 1994.

48. Bouchard C, Perusse L. Current status of the human obesity gene map. Obesity Res 4:81-90, 1996. 